\title{
Chain-growth polymerization enabling formation/ introduction of arylene groups into polymer main chains
}

\author{
Shingo Ito
}

Owing to the many advantages over step-growth polymerizations, chain-growth polymerization has been utilized in a variety of controlled polymer synthesis, including many important industrial processes. Chain-growth polymerization is generally used for alkenes and alkynes to form 'aliphatic main chains', such as alkylene and alkenylene units. In contrast, this method has rarely been applied to the construction of 'aromatic main chains' such as arylene units because of the poor variety of the corresponding aromatic monomers in polymer synthesis. Considering the increasing importance of arylene-containing polymers in academic and industrial societies, the development of controlled methods for the formation/introduction of arylene groups by chain-growth polymerization remains a challenging subject in polymer chemistry. In this review, the progress of chain-growth polymerization accompanied by formation/introduction of arylene groups into polymer main chains is reviewed.

Polymer Journal (2016) 48, 667-677; doi:10.1038/pj.2016.18; published online 9 March 2016

\section{INTRODUCTION}

The nature of polymers is largely determined by the structure of main chain. Thus polymers that contain arylene groups as the main chain are of high academic and industrial importance, because the arylene groups are responsible for various unique and interesting properties. The property of arylene-containing polymers is highly dependent on whether the main chain is fully conjugated or not. Arylenecontaining conjugated polymers, including polyarylenes and poly (arylenevinylene)s, have attracted much attention owing to their applications as optoelectronic devices, such as organic field-effect transistor and organic light-emitting diode. ${ }^{1-4}$ On the other hand, a strong motivation to synthesize arylene-containing non-conjugated polymers is their applications as engineering plastics exhibiting thermally durable properties, as exemplified by polycarbonates, aromatic polyamides and poly(ether ether ketone)s. ${ }^{5}$ Therefore, the development of novel controlled methods for the synthesis of polymers containing arylene groups is an important subject in polymer chemistry.

Methods to synthesize polymers are generally classified into two categories: step-growth polymerization and chain-growth polymerization. The former polymerization method proceeds via stepwise intermolecular reactions of bifunctional or multifunctional monomers. Many naturally occurring polymers, such as polypeptides, polysaccharides and nucleic acids, and some synthetic polymers, such as polyesters and polyamides, are produced by step-growth polymerization. On the other hand, chain-growth polymerization proceeds via successive intermolecular reactions between monomers and reactive sites on the polymer chain, with regeneration of the reactive sites at the end of each growth step. ${ }^{6,7}$ Hence, chain-growth polymerization methods offer many advantages over step-growth polymerization such as controlled molecular weights, narrow molecular-weight distributions and defined chain-end functional groups. Owing to these advantages, a variety of industrial processes for the production of synthetic polymers has been accomplished using the chain-growth polymerization method. Among them, the most representative examples are radical, anionic and cationic polymerizations of vinyl monomers, coordination-insertion polymerization of alkenes/alkynes and metathesis polymerizations. In general, almost all of these methods are applied to alkenes and alkynes to form 'aliphatic main chains', such as alkylene or alkenylene units. In contrast, the formation of 'aromatic main chains' such as arylene units by chain-growth polymerization remains a significant challenge in polymer synthesis. Over the past three decades, therefore, intensive efforts have been made by synthetic chemists to develop chain-growth polymerizations for forming polymers bearing arylene units in the main chain; this is the topic of the present review. It is worth noting that this review focuses on the introduction of arylene groups into the polymer main chain along with their formation and thus excludes polymerization of monomers bearing preformed intact arylene units, such as ring-opening metathesis polymerizations of arylene-containing monomers, ${ }^{8}$ catalyst-transfer condensation polymerizations ${ }^{9-18}$ and $\mathrm{S}_{\mathrm{RN}} 1$-type polycondensation reactions. $^{19}$ 


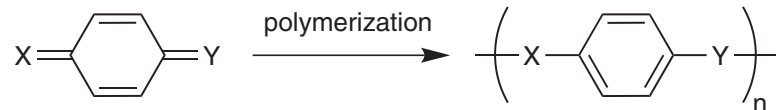<smiles>[R]C([R7])=c1ccc(=C([R7])[R])cc1</smiles>

1

p-quinodimethane

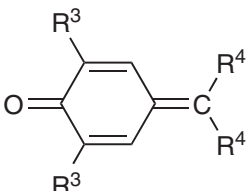

2

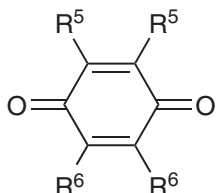

3

p-quinone<smiles>[R7]N=C1C=CC(=C(P)P)C=C1</smiles>

4

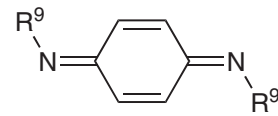

5

Scheme 1 Polymerization of $p$-quinodimethane and its analogs.

\section{p-ARYLENE UNITS}

\section{Polymerization of $p$-quinodimethanes and their analogs}

Established monomers for formation/introduction of $p$-arylene units are $p$-quinodimethanes 1 and their analogs $2-5$, generated by formal replacement of one or two of the methylidene carbon atoms in $\mathbf{1}$ by oxygen or nitrogen functionality (Scheme 1). The polymerization of such monomers produces polymers bearing a main chain of $-(\mathrm{X} \text {-arylene- } \mathrm{Y})_{\mathrm{n}}-$, regardless of whether the polymerization occurred via step-growth or chain-growth mechanisms. As quinonoid polymerization has a long-established history and its scope and limitations have been described in great detail, ${ }^{20-25}$ this review is mainly focused on the general aspects and recent developments of the polymerization.

The polymerization of $p$-quinodimethanes has attracted much attention as it affords poly( $p$-phenyleneethylene) (idiomatically called 'poly $(p$-xylylene $) ')^{22}$ Unsubstituted $p$-quinodimethane $\left(1: \mathrm{R}^{1}=\mathrm{R}^{2}=\mathrm{H}\right)$ can be generated by a variety of methods, including the pyrolysis of p-xylene, ${ }^{26}[2.2]$ paracyclophane ${ }^{27}$ and monofunctional or bifunctional monomers $\mathrm{XCH}_{2} \mathrm{ArCH}_{2} \mathrm{Y}$ (X, Y=hydro, halogen, carboxy, ammonium, sulfonium and so on), ${ }^{24}$ but the formed $p$-quinodimethane undergoes spontaneous polymerization without precise control via step-growth polymerization. The introduction of electronegative atoms or electron-withdrawing groups at the methylidene positions stabilizes the $p$-quinodimethane structure and enables their isolation and use in more controlled (co)polymerization, mainly by the radical mechanism. ${ }^{23-25}$ An interesting analog of $p$-quinodimethane is 10-methylene-9,10-dihydroanthryl-9-spiroarylcyclopropane $\mathbf{6}$, in which one of the methylidene groups in 9,10-anthraquinodimethane is formally cyclopropylated. Cho and Song ${ }^{28}$ reported, for the first time, that the polymerization of $\mathbf{6}$ was promoted by a radical initiator to produce poly(arylenepropylene) 7 (Scheme 2). The polymerization is driven by releasing the strain energy of the spiro structure and the subsequent aromatization of monomers. In the following papers, Mori and co-workers employed the reversible addition-fragmentation chain transfer method to this polymerization for synthesizing polymer $\mathbf{7}$ in a controlled manner. ${ }^{29-32}$

p-Quinone methides have offered chemistry similar to that of $p$-quinodimethane. Although unsubstituted p-quinone methide (2: $\left.\mathrm{R}^{3}=\mathrm{R}^{4}=\mathrm{H}\right)$ is an unstable species whose isolation is difficult, those with electron-withdrawing groups, such as cyano or

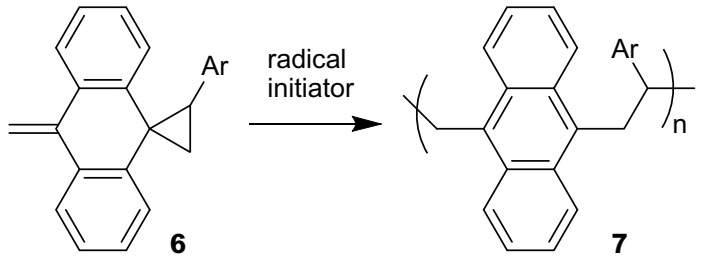

Scheme 2 Radical polymerization of 10-methylene-9,10-dihydroanthryl-9spiroarylcyclopropanes.

alkoxycarbonyl groups, at the methylidene positions $\left(\mathrm{R}^{4}\right)$ can be isolated and polymerized mainly by anionic polymerization. ${ }^{24,25}$ Cho and $\mathrm{Kim}^{33,34}$ developed the polymerization of $p$-quinone methide analog 8 , in which the methylidene group is formally cyclopropylated. Monomer $\mathbf{8}$ was not polymerized by a radical initiator but polymerized in the presence of an anionic initiator to form polymer 9. Based on the polymer structure, the polymerization was suggested to proceed via the nucleophilic attack of the anion intermediate to the more hindered carbon possessing the vinyl group, accompanied by ring opening of the cyclopropyl ring and aromatization (Scheme 3). ${ }^{33,34}$

Other $p$-quinodimethane analogs have also been investigated as monomers for homopolymerization and copolymerization. $p$-Benzoquinone $\left(3: \mathrm{R}^{5}=\mathrm{R}^{6}=\mathrm{H}\right)$ is usually used as an inhibitor for radical polymerization, and thus it generally does not undergo radical homopolymerization. In contrast, $p$-benzoquinone bearing electronwithdrawing groups, for example, $p$-chloranil $\left(3\right.$ : $\left.\mathrm{R}^{5}=\mathrm{R}^{6}=\mathrm{Cl}\right)$ and 2,3-dichloro-5,6-dicyano-p-benzoquinone (DDQ; $3: \mathrm{R}^{5}=\mathrm{Cl}$, $\mathrm{R}^{6}=\mathrm{CN}$ ), are amenable to alternating copolymerization with styrene or other alkenes in the presence of a radical initiator. ${ }^{35,36}$ However, it was subsequently reported that DDQ was spontaneously copolymerized with styrene in the absence of an initiator, ${ }^{37}$ suggesting ambiguity of the polymerization mechanism. p-Quinone methide imine bearing electron-withdrawing groups $\left(4: R^{7}=R^{8}=C N\right)^{38}$ was also homopolymerized and alternatingly copolymerized with styrene in the presence of 2,2'-azobis(isobutyronitrile) (AIBN) as a radical initiator. $p$-Quinone diimine 5 bearing substituents of $\mathrm{R}^{9}=\mathrm{SO}_{2} \mathrm{Ph}$, $\mathrm{CO}_{2} \mathrm{Et}$ and $\mathrm{COPh}$ exhibited low reactivity for homopolymerization but alternatingly copolymerized with vinylarenes and vinyl ethers in the presence of AIBN as a radical initiator. ${ }^{39,40}$

\section{Ring-opening metathesis polymerization of bicyclic alkenes as $p$-quinodimethane equivalents}

Poly( $p$-arylenevinylene)s are an important $\pi$-conjugated polymer, which exhibits excellent material properties such as high electron conductivity when doped and photoluminescence and electroluminescence. ${ }^{41-43}$ In general, poly( $p$-arylenevinylene)s are prepared by step-growth polymerization via polycondensation. ${ }^{44-46}$ In this synthetic route, however, it is difficult to control molecular weights and polymer sequences. Grubbs and co-workers developed chain-growth polymerizations to synthesize poly( $p$-arylenevinylene)s via two-step processes. Molybdenum-catalyzed ring-opening metathesis polymerization (ROMP) of functionalized barrelene derivatives, biscarbonate 10, afforded polymer 11. The following elimination of carbon dioxide and methanol under thermal conditions led to the formation of poly( $p$-phenylenevinylene) 12 with high number average molecular weights $\left(M_{\mathrm{n}}\right)$ of 46000-63000 and low molecular weight distributions of 1.2-1.3 (Scheme 4a). ${ }^{47}$ Similarly, the ROMP of alkylated benzobarrelenes $\mathbf{1 3}$ followed by oxidative dehydrogenation in the presence of DDQ was also developed to produce poly(naphthalene-1,4-diylvinylene)s 15 (Scheme $4 \mathrm{~b}){ }^{48-50}$ 


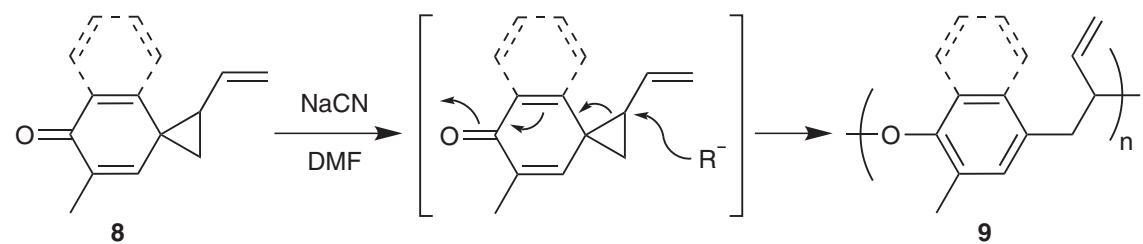

Scheme 3 Anionic polymerization of spiroquinones.
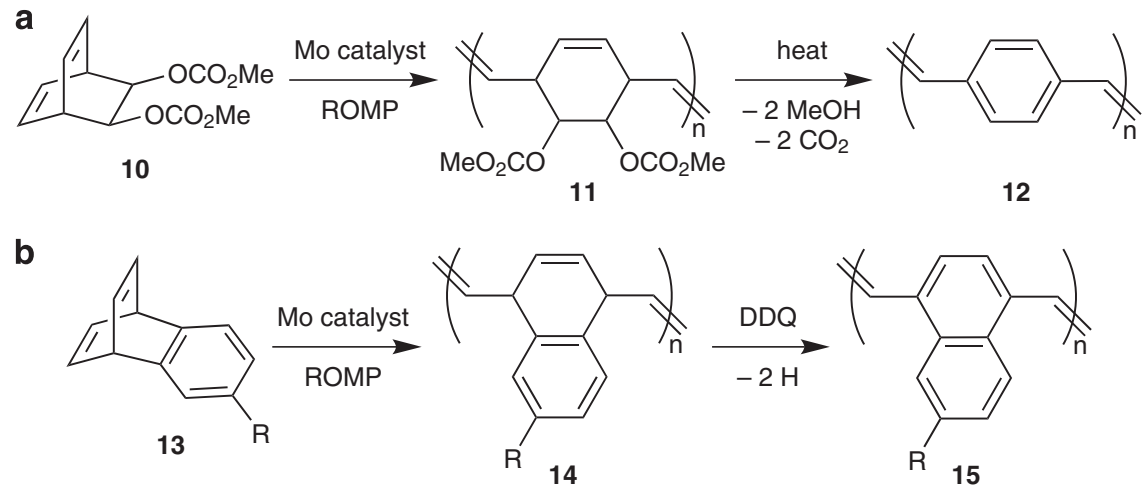

Scheme 4 Ring-opening metathesis polymerization of [2.2.2]bicyclic alkenes, (a) functionalized barrelene derivatives and (b) benzobarrelenes, followed by aromatization.

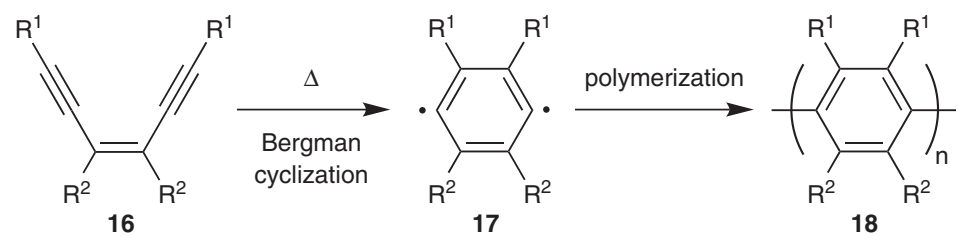

Scheme 5 Polymerization of $p$-didehydrobenzenes formed by the Bergman cyclization.

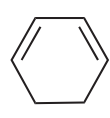

19

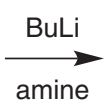

amine

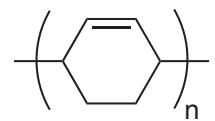

20

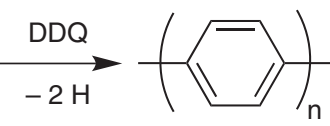

21
Scheme 6 Living anionic polymerization of cyclohexa-1,3-diene.

The presence of a fused benzene ring would be essential to promote dehydrogenation.

\section{Polymerization of $p$-didehydroarene and their equivalents}

The simplest candidate of monomers for efficient introduction of $p$-arylene units is $p$-didehydroarene (idiomatically called ' $p$-aryne'), which was first generated by Jones and Bergman ${ }^{51}$ by pyrolysis of (Z)-hexa-3-en-1,5-diyne $16\left(\mathrm{R}^{1}=\mathrm{R}^{2}=\mathrm{H}\right)$ in 1972. Homopolymerization of $p$-didehydroarene is a potentially useful method because the resulting poly( $p$-phenylene) $\mathbf{1 8}$ has received considerable attention because of its high stability, electrical conductivity and optoelectronic properties. ${ }^{42,52,53}$ However, the intrinsic instability of $p$-didehydroaren ${ }^{54}$ makes its use in polymerization difficult. The only known example includes the polymerization of 1,4-diradical intermediates 17 generated by the Bergman-type cyclization of enediyne-type compounds 16 (Scheme 5 ), ${ }^{55-57}$ but the details are not covered in this review because it is step-growth polymerization.
In order to achieve the controlled synthesis of poly(p-phenylene)s via chain-growth polymerization, chemists have focused on the polymerization of $p$-didehydrobenzene equivalents. The first attempts employed cyclohexa-1,3-diene 19 as a monomer. In reports in the 1950-1960s, ${ }^{58-61}$ the Ziegler-type catalysts were used to synthesize polycyclohexadienes, which contained a certain percentage of 1,2- and 1,3-cyclohexenylene units along with the desired 1,4-cyclohexenylene units. The subsequent aromatization by dehydrogenation or bromination/dehydrobromination afforded poor-quality poly (p-phenylene)s. ${ }^{58,59,61}$ In 1997, the living anionic polymerization of cyclohexa-1,3-diene 19 to form 1,4-regioregular polymers 20 was accomplished using the BuLi/amine system (Scheme 6). ${ }^{62}$ The ratio of 1,2- and 1,4-cyclohexenylene units in the polymer chain can be controlled up to almost perfect 1,4-selectivity by changing alkyllithium and amine ligands. ${ }^{63-65}$ Subsequent dehydrogenation of the 1,4-regioregular polymer was accomplished using DDQ to form regioregular poly( $p$-phenylene) $21 .{ }^{66}$ The living anionic polymerization method could be applied to copolymerization to synthesize block, ${ }^{67-69}$ random, ${ }^{70}$ quasi-alternating ${ }^{71}$ or $\mathrm{C}_{60}$-graft ${ }^{72,73}$ copolymers, in which subsequent dehydrogenation produces $p$-phenylene groups in the copolymers.

In this regard, functionalized cyclohexa-1,3-dienes, including cyclohexa-3,5-diene-1,2-diyl dibenzoate (22a) and 5,6-bis(trimethylsiloxy) cyclohexa-3,5-diene (22b), are promising candidates for chain-growth polymerization to obtain poly( $p$-phenylene)s. Radical polymerization of 22a produced the corresponding polymers, but the products 
a
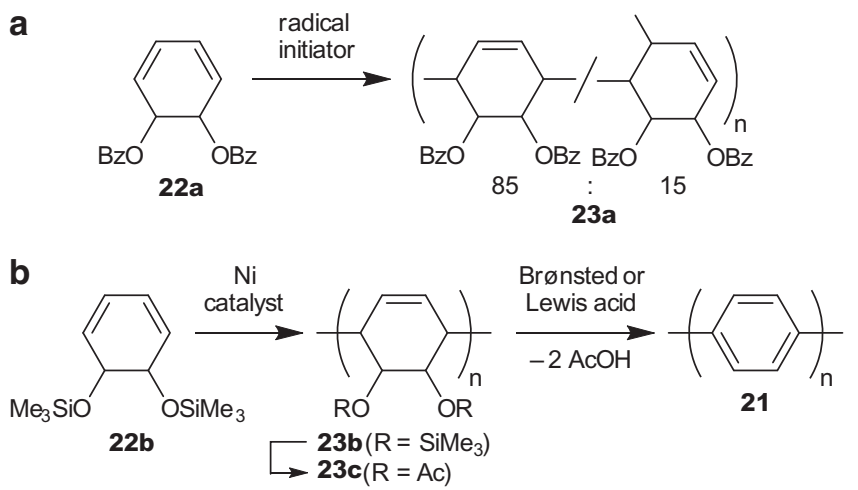

Scheme 7 (a) Radical polymerization of cyclohexa-3,5-diene-1,2-diyl dibenzoate and (b) nickel-catalyzed coordination-insertion polymerization of 5,6-bis(trimethylsiloxy)cyclohexa-1,3-diene to form poly( $p$-phenylene).<smiles>Cc1cccc(C)c1</smiles>

24<smiles></smiles>

26

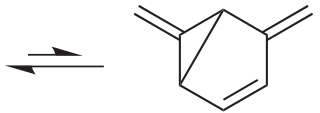

25

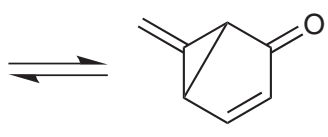

27
Scheme 8 Valence tautomerization of (a) m-quinodimethane and (b) $m$-quinone methide.

contained about $10-15 \%$ of 1,2-linkages along with $85-90 \%$ of 1,4-linkages (Scheme 7a). ${ }^{74-76}$ The non-regioregular polymers were converted to the corresponding poly( $p$-phenylene)s by thermal acid elimination, leading to the deterioration of molecular weights during the aromatization process. ${ }^{76,77}$ Following these reports, Grubbs and co-workers succeeded in obtaining the perfect regioregular polymers by using transition metal catalysis. ${ }^{77-79}$ The regioregular and stereoregular nickel-catalyzed polymerization of $\mathbf{2 2 b}$ afforded polymer $\mathbf{2 3 b}$ $\left(M_{\mathrm{n}}=20000-50000\right)$ containing only 1,4-linkages (Scheme $\left.7 \mathrm{~b}\right) .{ }^{77}$ The following conversion of $\mathbf{2 3 b}$ into acetate $\mathbf{2 3} \mathbf{c}$ was needed before elimination of acetic acids for the production of poly( $p$-phenylene) 21. When the aromatization of $23 \mathrm{c}$ was induced under thermal conditions, the onset of chain degradation occurred before the onset of aromatization. Consequently, the assistance by Brønsted or Lewis-acid catalysis was essential for smooth elimination of acetic acids to produce poly( $p$-phenylene) 21 without significant decrease of molecular weight. ${ }^{79}$

\section{m-ARYLENE UNITS}

Compared with the polymerization methods to form $p$-arylene units, fewer methods have been developed for the synthesis of $m$-arylene unit-containing polymers via chain-growth polymerization. This could be partly attributed to the absence of $m$-didehydroarene polymerization. $m$-Didehydroarene (idiomatically called ' $m$-aryne') $)^{54}$ has received less attention than the $p$ - and $o$-analogs that have offered rich chemistry. Although $m$-didehydroarenes can be generated by various methods, including (flash vacuum) pyrolysis and photolysis, ${ }^{80-82}$ there are no literature reports of the polymerization of $m$-didehydroarenes.
In this sense, $m$-quinonoids are the only candidate available for formation/introduction of $m$-arylene units. Compared with $p$ - and $o$ quinonoids, $m$-quinonoids are less stable because of their non-Kekulé structure. For example, $m$-quinodimethane is known to exist as a diradical species $\mathbf{2 4}$ rather than a closed tautomer structure such as $\mathbf{2 5}$ (Scheme 8a), ${ }^{83}$ although its polymerization has not been reported. $m$ Quinone methide also has a non-Kekulé structure and thus can be isolated in the form of a valence tautomer, 6-methylenebicyclo[3.1.0] hex-3-en-2-one 27 (Scheme 8b), which was polymerized in a noncontrolled manner by pyrolysis or photolysis to produce insoluble polymeric materials. ${ }^{84}$ In that sense, the only example of chain-growth polymerization of $m$-quinonoids includes the polymerization of monomer 28, a valence tautomer of $m$-naphthoquinone methide (Scheme 9). ${ }^{85}$ Compound 28 was polymerized in the presence of AIBN as a radical initiator but not with cationic and anionic initiators. The polymerization was accompanied by the ring opening aromatization to obtain head-to-tail polymer 29 with $M_{\mathrm{n}}$ of 3200 . Copolymerization of monomer $\mathbf{2 8}$ with methyl methacrylate was also accomplished using a radical initiator to produce the corresponding random copolymer 30 with $M_{\mathrm{n}}$ of 2200-70000 depending on the content of methyl methacrylate.

\section{o-ARYLENE UNITS}

Polymerization of $o$-quinodimethanes

Polymerization of $o$-quinodimethanes ${ }^{24,86}$ is a powerful method to afford poly (o-phenyleneethylene). As o-quinodimethane is an unstable and non-isolable species, it is used after in situ generation from a suitable precursor. In a seminal paper, Errede ${ }^{87}$ investigated the preparation and properties of $o$-quinodimethane 32 generated by flash vacuum pyrolysis of $o$-methylbenzyl(trimethyl)ammonium hydroxide, 31 (Scheme 10). The in situ generated compound 32 was trapped as the form of dibenzocyclooctadiene 33 and spirodimer 34 after quenching at low temperature. ${ }^{87}$ Although compound 33 was thermally stable, spirodimer $\mathbf{3 4}$ was polymerized upon heating to form poly (o-phenyleneethylene) 35 .

Another representative precursor of $o$-quinodimethanes is benzocyclobutene. ${ }^{88}$ Thermal isomerization of non-substituted benzocyclobutene into $o$-quinodimethane occurs above $200^{\circ} \mathrm{C}$, which would prohibit its use for controlled chain-growth polymerization. Chino and Endo ${ }^{89}$ reported that the introduction of functional groups into the cyclobutene ring has a large influence on the isomerization temperature. For example, the introduction of an electron-donating methoxy group (36a; $\mathrm{R}=\mathrm{OMe}$ ) lowered the temperature to around $100^{\circ} \mathrm{C},{ }^{89}$ which is a suitable temperature to perform a variety of polymerization methods, including radical, ${ }^{90,91}$ cationic $^{92}$ and anionic $^{92}$ polymerizations, to afford polymer 38a (Scheme 11). Subsequent treatment of polymer 38a $\left(M_{\mathrm{n}}=5600\right)$ with $p$-toluenesulfonic acid at $60^{\circ} \mathrm{C}$ led to the formation of poly $(o$-phenylenevinylene) 39 with a slight decrease of molecular weight $\left(M_{\mathrm{n}}=3500\right) .{ }^{90,91}$ The introduction of the electron-withdrawing cyano group also lowered the isomerization temperature to $120-150{ }^{\circ} \mathrm{C}$, inducing radical polymerization to afford the corresponding polymers with molecular weights of $M_{\mathrm{n}}=1500-4700 .^{93,94}$ In the case of the siloxy-substituted substrate $36 \mathbf{b} \quad\left(\mathrm{R}=\mathrm{OSiMe}_{3}\right)$, group-transfer polymerization of $\mathbf{3 6} \mathbf{b}$ was shown to be available to afford polymer 38b with low molecular weights of $M_{\mathrm{n}}$ up to $2000 .{ }^{95}$

\section{Polymerization of $o$-diisocyanoarenes}

A significant milestone in polymer synthesis via formation/ introduction of $o$-arylene groups is the living polymerization of 1,2-diisocyanoarenes to form poly(quinoxaline-2,3-diyl)s. In 1990, 
<smiles>C=C1C2C(=O)c3ccccc3C2C1c1ccccc1CC(C)(C)C(C)(C)C(C)(C)C(C)(C)C(C)(C)CC(C)(C)Oc1cc(CC(C)(C)C)cc2ccccc12</smiles>

Scheme 9 Homo- and copolymerization of a valence tautomer of $m$-naphthoquinone methide.<smiles>CCc1cccc(C[N+](C)(F)F)c1C</smiles>

31

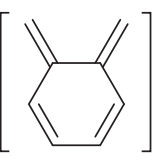

32<smiles>C=C1C=CC=CC12CCc1ccccc1C2</smiles>

33
34

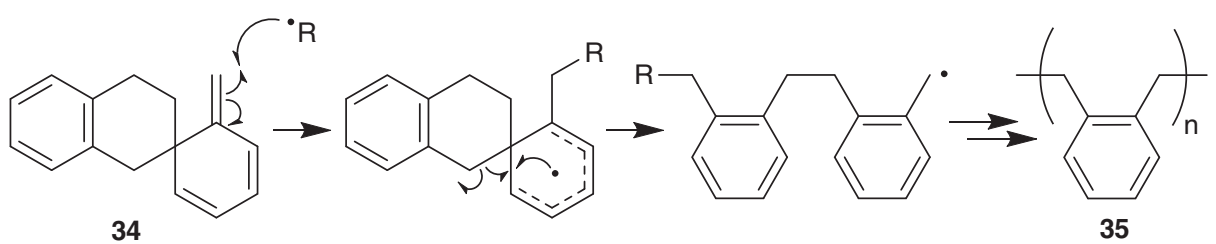

Scheme 10 Pyrolysis of $o$-methylbenzyl(trimethyl)ammonium hydroxide and polymerization of the formed spirodimer of $o$-quinodimethane.

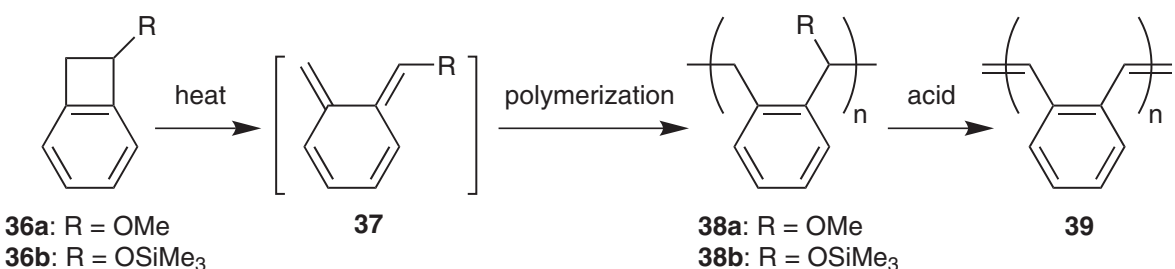

Scheme 11 Polymerization of o-quinodimethane formed by pyrolysis of benzocyclobutenes.<smiles>C=Nc1c(C)c(C)c(C)c(C)c1N=C</smiles>

40

$\downarrow R-M L_{n}$

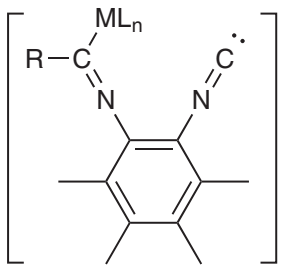

A

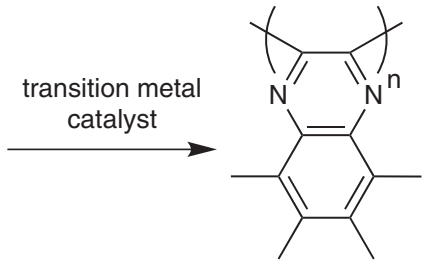

41

$\uparrow$

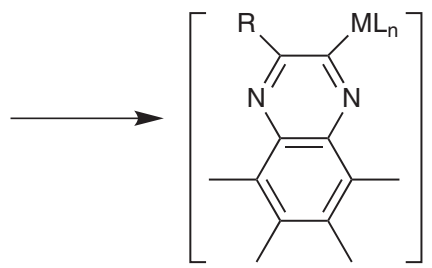

B
Scheme 12 Metal-catalyzed living polymerization of diisocyanoarenes to form poly(quinoxalin-2,3-diyl)s.
Ito et al. ${ }^{96}$ developed palladium-catalyzed polymerization of 1,2-diisocyanoarene $\mathbf{4 0}$ to produce poly(quinoxaline-2,3-diyl)s 41 (Scheme 12). The reaction proceeds by successive insertion of isocyano groups into the metal-carbon bond of the catalyst $(\mathbf{4 0} \rightarrow \mathrm{A} \rightarrow$ B). The stable (quinoxalinyl)palladium moiety $\mathbf{B}$ in the polymer chain end is essential for realizing living polymerization. As the poly (quinoxaline-2,3-diyl)s adopt a stable helical structure, it can be optically active if the polymerization proceeds with a preference for a single-handed helix. In 1992, the first enantioselective polymerization was accomplished to form optically active poly(quinoxaline-2,3diyl)s possessing a single-helical helix. ${ }^{97}$ Following these seminal reports, the chemistry based on helical poly(quinoxaline-2,3-diyl)s has been greatly expanded mainly by Suginome and co-workers for applications to asymmetric catalysis ${ }^{98-101}$ and chirality-switching materials. ${ }^{98,102-105}$

\section{Polymerization of 3,3-diarylcyclopropenes via 1,4-rhodium} migration

Shintani et al. ${ }^{106}$ reported a new mode of metal-catalyzed polymerization to form novel $o$-arylene-containing polymers. The rhodium- 

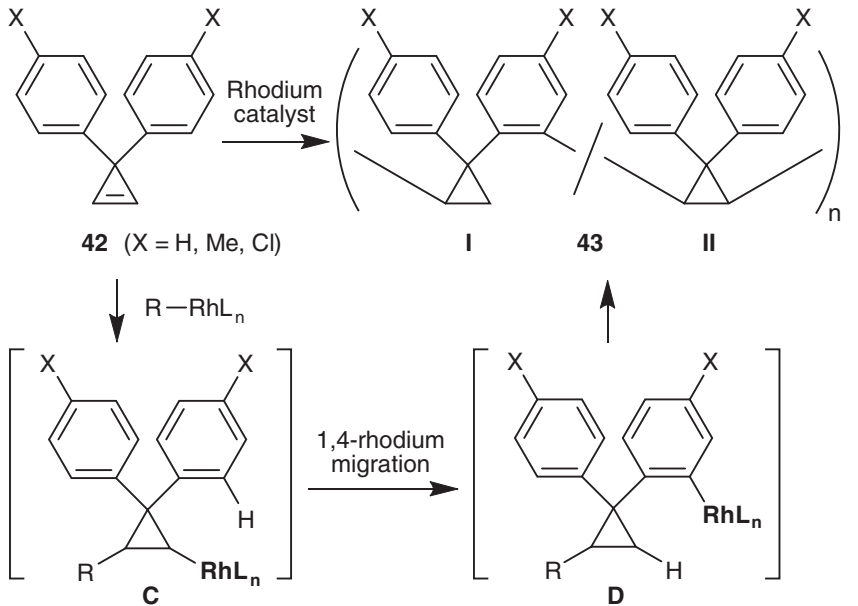

Scheme 13 Rhodium-catalyzed polymerization of 3,3-diarylcyclopropene via 1,4-rhodium migration.
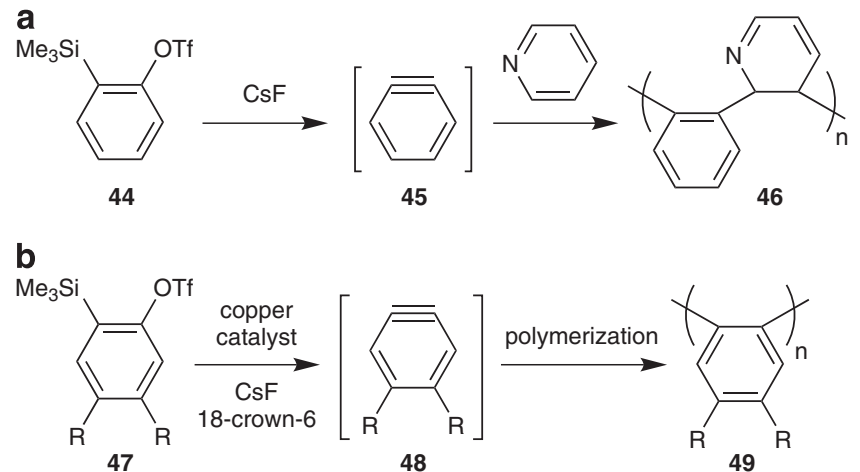

Scheme 14 Benzyne polymerizations: (a) copolymerization of benzyne and pyridine and (b) homopolymerization of arynes.

catalyzed polymerization of 3,3-diarylcyclopropenes 42 proceeded through the insertion of $\mathbf{4 2}$ into a rhodium-carbon bond and a subsequent 1,4-rhodium migration $(\mathbf{C} \rightarrow \mathbf{D})$ to produce poly (cyclopropylene-o-phenylene)s 43 with $M_{\mathrm{n}}$ of 8000-27000 (Scheme 13). ${ }^{106}$ Although the selectivity of 1,4-rhodium migration was not perfect, the ratio of cyclopropylene-o-phenylene unit I to cyclopropylene unit II was improved up to $91: 9$ by optimizing the rhodium catalyst, polymerization initiator and concentration. In the sequence of the polymerization, aryl groups are transformed into arylene groups via in situ 1,4-rhodium migration, which allows access to a unique main-chain structure that is difficult to construct by conventional polymerization methods.

\section{Polymerization of arynes (o-didehydroarenes)}

The simplest ideal monomer for efficient introduction of $o$-arylene units is an aryne-O-didehydroarene-formed by abstraction of two neighboring hydrogen atoms from an arene compound. Since their first synthetic report in 1902, ${ }^{107,108}$ arynes have served as useful intermediates in organic synthesis for $>100$ years. ${ }^{109-112}$ Despite their significant utility, arynes had been an elusive monomer for polymerization until recently. If aryne could be (co)polymerized, it would allow the direct synthesis of $o$-arylene-containing polymers such as poly(o-arylene)s. In contrast to extensively studied $p$ - and $m$-connected analogs, poly $(o$-arylene $) s$ have been the least studied

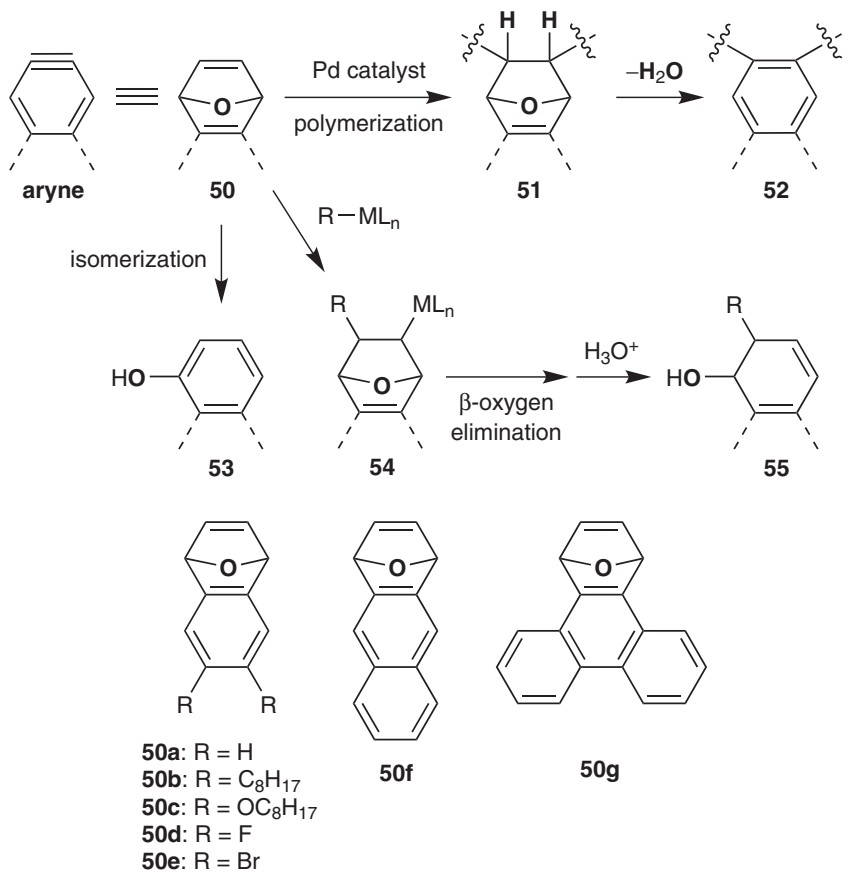

Scheme 15 [2.2.1]Oxabicyclic alkenes as an aryne equivalent: polymerization and possible side reactions.

class of $\pi$-conjugated compounds, which adopt helical conformation along their twisted main chains.

The first attempt to polymerize benzyne was reported by Ihara et al. ${ }^{113}$ in 2005 . They tried to polymerize benzyne 45 , prepared by the reaction of $o$-silylphenyl triflate $\mathbf{4 4}$ with cesium fluoride, by using a wide range of initiators under various conditions, but all the attempts resulted in no polymerization. Instead, they found that the copolymerization of benzyne with pyridine proceeded to give the corresponding alternating copolymer 46 (Scheme 14a). Ten years later, in 2015, Mikami and Uchiyami reported the first copper-catalyzed homopolymerization of benzynes (Scheme 14b). ${ }^{114}$ Benzyne monomers 48 were prepared by reaction of $o$-silylaryl triflate 47 with fluoride anion. The use of copper(I) catalysts was effective to promote the polymerization into poly(o-phenylene)s 49 with $M_{\mathrm{n}}$ of 2400-13 800. In particular, when Lipshutz cuprate $\left(\mathrm{Bu}_{2} \mathrm{Cu}(\mathrm{CN}) \mathrm{Li}_{2}\right)$ or copper cyanide $(\mathrm{CuCN})$ was used, matrix-assisted laser desorption ionization time-of-flight mass analysis revealed that the obtained polymer has a cyano group $(\mathrm{CN})$ as an initiation chain end. Based on the results, the authors claimed that the polymerization was initiated by addition of cyanide anion $\left({ }^{-} \mathrm{CN}\right)$ to a benzyne and proceeded via successive insertion of benzynes in a chain-growth manner.

Polymerization of aryne equivalents (formal aryne polymerization) As stated in previous section, aryne was a difficult monomer to polymerize and still remains so. In order to expand the utility and variety of aryne polymerization chemistry, we saw the need for development of novel polymerization methods that can utilize more stable and controllable monomers. In our research, therefore, we focus on a synthetic equivalent of arynes, [2.2.1] oxabicyclic alkenes 50, as monomers for polymerization. [2.2.1] Oxabicyclic alkenes have been employed as useful building blocks and intermediates in organic synthesis, especially for efficient construction of various synthetically useful carbocycles and heterocycles, which are not accessible by 

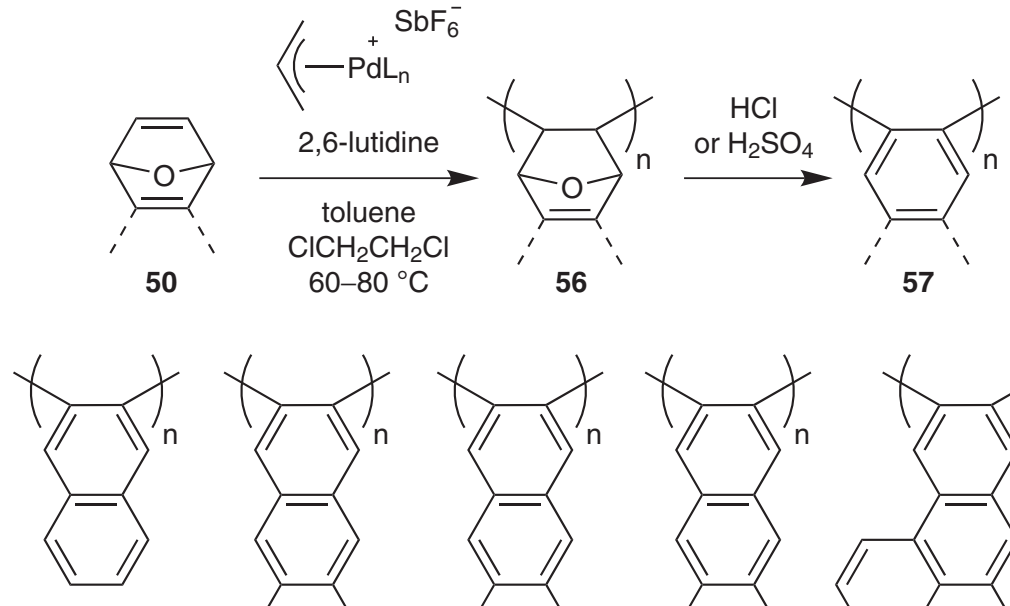

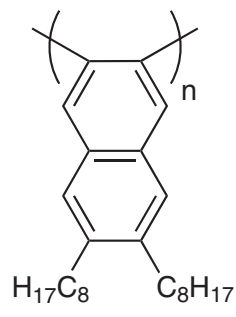

57b

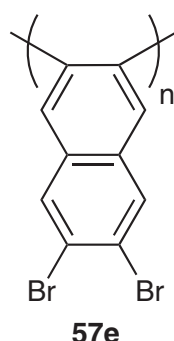

$57 e$

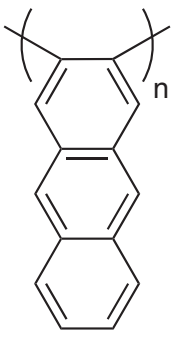

57

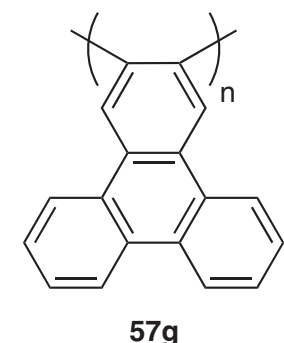

$57 \mathrm{~g}$

Scheme 16 Formal aryne polymerization using [2.2.1]oxabicyclic alkenes as an aryne equivalent to form poly(o-arylene)s.
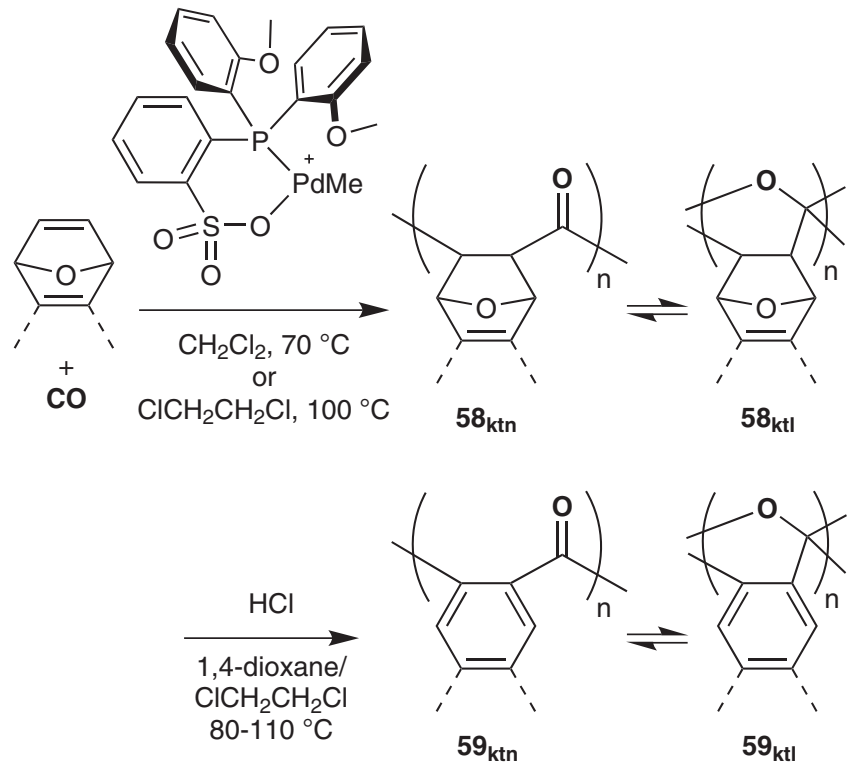

Scheme 17 Formal aryne/carbon monoxide alternating copolymerization to form aromatic polyketones/polyketals.

other conventional methods. ${ }^{115-118}$ However, the monomers have rarely been used as a monomer for polymerization. ${ }^{19-122}$ As shown in Scheme 15, polymerization of $\mathbf{5 0}$, if successful, affords the corresponding polymer $\mathbf{5 1}$, which can be converted to $o$-arylene units 52 by subsequent dehydration. Importantly, in the whole process, monomer $\mathbf{5 0}$ functions as an aryne equivalent, enabling the formation/ introduction of $o$-arylene groups in the main chain of polymers. A potential side reaction in the coordination-insertion polymerization of $\mathbf{5 0}$ is the metal-catalyzed isomerization of $\mathbf{5 0}$ into 1-hydroxyarenes 53. ${ }^{123,124}$ The polymerization may also be hampered by $\beta$-oxygen elimination from intermediates $\mathbf{5 4}$, formed by the insertion of $\mathbf{5 0}$ into a metal-alkyl species $\left(\mathrm{R}-\mathrm{ML}_{\mathrm{n}}\right)$, to give ring-opened products $55 .{ }^{115-118}$

First, we developed homopolymerization of aryne equivalents 50. ${ }^{125}$ In order to achieve polymerization, a wide range of transition-metal catalysts, ligands and solvents were screened using monomer 50a.
As a result, the polymerization was found to be successfully catalyzed by a cationic palladium complex $\left(\eta^{3}\right.$-allyl $) \mathrm{Pd}^{+} \mathrm{SbF}_{6}{ }^{-}$stabilized by 2,6-lutidine (Scheme 16). An important role of 2,6-lutidine is to suppress monomer isomerization even under high-temperature conditions: In the absence of 2,6-lutidine, the monomer tends to be rapidly isomerized into 1-hydroxyarene 53. In addition, the use of combined solvents, toluene and 1,2-dichloroethane was also essential to improve the polymer yield and molecular weight. Toluene is needed to stabilize the cationic palladium catalyst ${ }^{126}$ and suppress $\beta$-oxygen elimination from 54 during chain propagation. A halogenated co-solvent, 1,2-dichloroethane, is required to dissolve the cationic palladium catalyst. The following dehydration of polymer 56 was accomplished by treatment with hydrogen chloride or concentrated sulfuric acid to afford the corresponding poly(o-arylene)s $\mathbf{5 7 .}$ The present two-step method was demonstrated to synthesize poly (naphthalene-2,3-diyl)s, which bear hydro groups 57a $\left(M_{\mathrm{w}}=3900\right)$, electron-donating alkyl groups 57b $\left(M_{\mathrm{w}}=7000\right)$ and electronwithdrawing bromo group 57e $\left(M_{\mathrm{w}}=1200\right)$, in good yields. The method could also be applied to monomers with longer $\pi$-conjugate systems in order to synthesize poly(anthracene-2,3-diyl) $\mathbf{5 7 f}$ $\left(M_{\mathrm{w}}=6300\right)$ and poly(triphenylene-2,3-diyl) $57 \mathrm{~g}\left(M_{\mathrm{w}}=800\right)$.

The advantage of the present 'formal aryne polymerization' method is that the aryne equivalents could be used for copolymerization as they are a stable monomer, unlike an unstable aryne. Thus we targeted the copolymerization with carbon monoxide, which leads to the formation of aromatic polyketones/polyketals. ${ }^{127}$ Aromatic polyketones, ${ }^{128,129}$ bearing the main chain consisting of arylene and carbonyl groups, have received much attention because of their potential applications as superengineering plastics. ${ }^{130-132}$ However, the range of accessible aromatic polyketones has been limited, and all the methods rely on step-growth condensation polymerization, ${ }^{128-134}$ rather than chain-growth polymerization. Thus we focused on the transition-metal-catalyzed alternating copolymerization of alkenes and carbon monoxide, which produces aliphatic polyketones bearing saturated aliphatic main chains. ${ }^{135-138}$ Although the methods have never been applied to an 'aromatic comonomer' such as aryne, we envisioned that the use of aryne equivalents would achieve the synthesis of aromatic polyketones with alternating $o$-arylene and carbonyl linkages. 

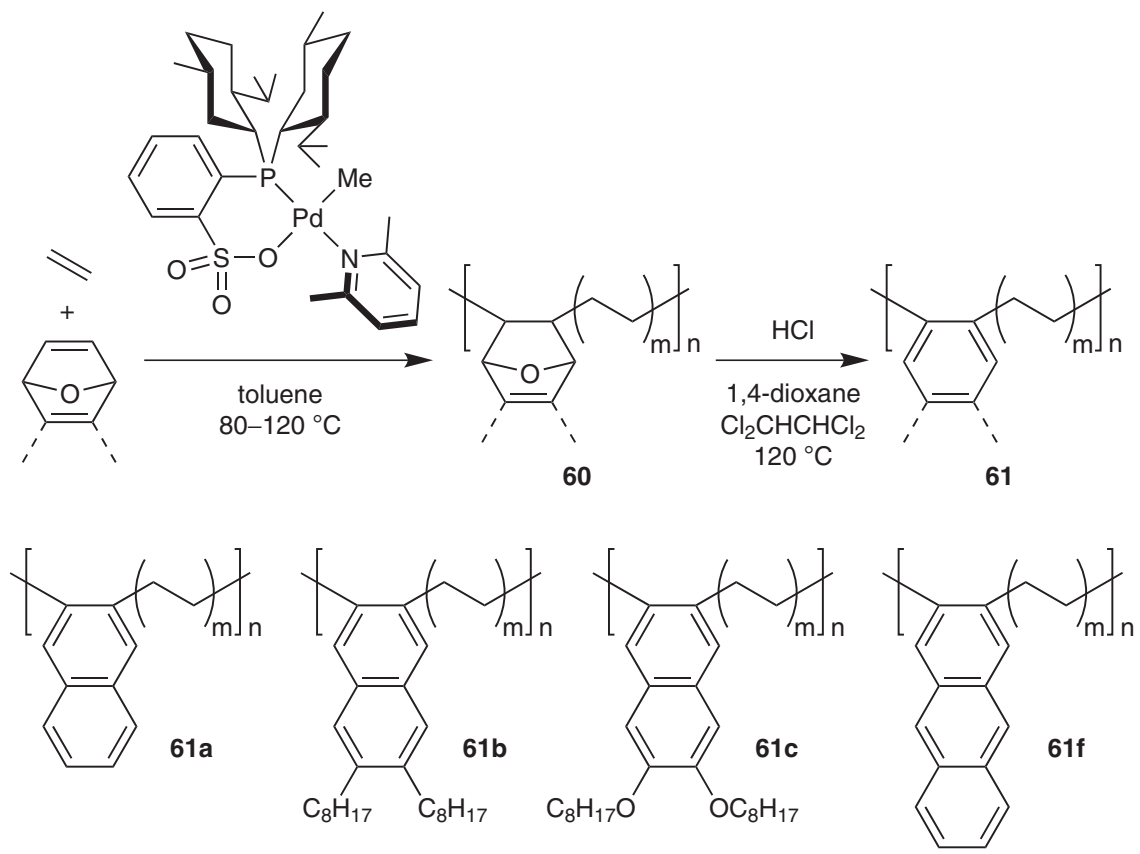

Scheme 18 Formal aryne/ethylene copolymerization to form o-arylene-containing polyethylenes.

Extensive catalyst screening for polymerization of [2.2.1] oxabicyclic alkenes 50a revealed that the use of palladium/phosphine-sulfonate catalysts $^{136-138}$ was effective to produce polymers $\mathbf{5 8}$ in terms of polymer yield and molecular weights (Scheme 17). The optimum reaction conditions enabled the synthesis of various copolymers 58 from 2,3-didehydronaphthalene equivalents bearing hydro groups $\mathbf{5 0 a}$, electron-donating groups $50 \mathrm{~b}$ and $50 \mathrm{c}$ and electron-withdrawing groups $\mathbf{5 0 d}$ as well as 2,3-didehydroantracene equivalent $\mathbf{5 0 f}$. The obtained polymers have a mixed structure of polyketone form $\mathbf{5 8} \mathbf{k t n}$ and polyketal form $\mathbf{5 8}$ ktl, in which the ratio of $\mathbf{5 8}_{\mathrm{ktn}} / \mathbf{5} \mathbf{8}_{\mathrm{ktl}}$ depends on the monomer used. Subsequent dehydration reactions of $\mathbf{5 8 a}-\mathbf{c}$ and $\mathbf{5 8 f}$ were accomplished by the treatment of polymers with hydrogen chloride to obtain aromatic polyketone/polyketals 59. Although polymers 59a and 59f were insoluble in common organic solvents, polymers $\mathbf{5 8 b}$ and $\mathbf{5 8 c}$ showed good solubility, which enabled to determine their molecular weights to be $M_{\mathrm{n}}$ of $4000-4800$. The resulting copolymers $\mathbf{5 9}$ were amorphous solids, which exhibited high $5 \%$-weight-loss temperatures at $281-317^{\circ} \mathrm{C}$.

Finally, we focused our attention on the formal aryne copolymerization with ethylene, which produces $o$-arylene-containing polyethylenes. The introduction of functional groups or different comonomers into linear polyethylenes is effective for the modification of both surface and materials properties. ${ }^{136}$ Toward the end, a range of comonomers, including polar monomers ${ }^{136-139}$ and carbon monoxide, ${ }^{135}$ have thus far been incorporated, but the use of aryne or its congeners for the introduction of $o$-arylene linkage has been unexplored. Thus we employed our formal aryne polymerization strategy for the copolymerization with ethylene (Scheme 18). ${ }^{140}$

Copolymerization of aryne equivalents $\mathbf{5 0}$ and ethylene, followed by acid-induced dehydration, was found to proceed to generate the corresponding copolymers $\mathbf{6 1}$ containing $o$-arylene units in the main chain when palladium/alkylphosphine-sulfonate complexes ${ }^{141-143}$ were used as a catalyst. In particular, the use of a phosphine-sulfonate ligand bearing bulky methyl groups on the phosphorus atoms was essential to produce copolymers with high $M_{\mathrm{n}}$ of up to 18200 . It is worth noting that other transition metal catalysts that are capable of promoting ethylene/polar monomer copolymerization, such as palladium/o-diimine, ${ }^{144,145}$ nickel/imine-phenolate ${ }^{146}$ and palladium/ bisphosphine-monoxide, ${ }^{147}$ produced no polymer. Nuclear magnetic resonance analysis of the obtained copolymers 61 revealed that the copolymers have a linear polyethylene backbone without detectable alkyl branching and that the introduced arene units were attached mainly to the main chain as an $o$-arylene group and partly to the chain end as an aryl group. The copolymers exhibited linear low-density polyethylene-like thermal properties as determined by differential scanning calorimetric measurements.

\section{CONCLUSION}

Despite significant advances in polymer synthesis, the introduction of arylene units relies largely on step-growth polymerization, and it is still difficult to achieve controlled synthesis of arylene-containing polymers based on chain-growth polymerization. A serious bottleneck is the limited variety of monomers that enable the introduction of arylene units, that is, chemists need to use unstable and uncontrollable monomers, such as quinonoids and didehydroarenes. Hence, many of the successful (co)polymerizations enabling the formation/ introduction of arylene groups in the main chain of polymers in a chain-growth manner resulted from the use of stable surrogates or valence tautomers of the otherwise unstable monomers. Although the molecular weights of the resulting polymers were relatively low, the methods in this review offer the versatile and useful methods for the synthesis of various arylene-containing polymers via chain-growth polymerization.

\section{CONFLICT OF INTEREST}

The author declares no conflict of interest.

\section{ACKNOWLEDGEMENTS}

I thank Professor Kyoko Nozaki (UTokyo) for her generous support and encouragement and all the co-workers and collaborators for their contributions to the work cited in this review. I also thank the reviewers of the manuscript for their valuable comments and suggestions given during the review process. 
This work was financially supported by Grant-in-Aid for Exploratory Research (No. 24655096) from Ministry of Education, Culture, Sports, Science and Technology (MEXT)/Japan Society for the Promotion of Science (JSPS), the Ogasawara Foundation for the Promotion of Science \& Engineering, the TonenGeneral Sekiyu Foundation and the Yazaki Memorial Foundation for Science and Technology.

1 Conjugated Polymers: Theory, Synthesis, Properties, and Characterization (eds Skotheim, T. A. \& Reynolds, J. R.) (CRC Press, Boca Raton, FL, USA, 2007).

2 Conjugated Polymers: Processing and Applications (eds Skotheim, T. A. \& Reynolds, J.) (CRC Press, Boca Raton, FL, USA, 2007).

3 Design and Synthesis of Conjugated Polymers (eds Leclerc, M. \& Morin, J.-F.) (Wiley-VCH Veriag GmbH \& Co. KGaA, Weinheim, Germany, 2010)

4 Okamoto, K. \& Luscombe, C. K. Controlled polymerizations for the synthesis of semiconducting conjugated polymers. Polym. Chem. 2, 2424-2434 (2011).

5 Handbook of Thermoplastics 2nd edn (eds Olabisi, O. \& Adewale, K.) (CRC Press, Boca Raton, FL, USA, 2016).

6 International Union of Pure and Applied Chemistry. Compendium of Chemical Terminology 2nd edn (the "Gold Book"), (Blackwell Scientific Publications, Oxford, UK, 1997).

7 Jenkins, A. D., Kratochvíl, P., Stepto, R. F. T. \& Suter, U. W. Glossary of basic terms in polymer science. Pure Appl. Chem. 68, 2287-2311 (1996).

8 Bunz, U. H. F., Mäker, D. \& Porz, M. Alkene metathesis - a tool for the synthesis of conjugated polymers. Macromol. Rapid Commun. 33, 886-910 (2012).

9 Yokozawa, T. \& Yokoyama, A. Chain-growth polycondensation for well-defined condensation polymers and polymer architecture. Chem. Rec. 5, 47-57 (2005).

10 Yokoyama, A. \& Yokozawa, T. Converting step-growth to chain-growth condensation polymerization. Macromolecules 40, 4093-4101 (2007).

11 Yokoyama, A. \& Yokozawa, T. Development of catalyst-transfer condensation polymerization. synthesis of $\pi$-conjugated polymers with controlled molecular weight and low polydispersity. J. Polym. Sci. A Polym. Chem. 46, 753-765 (2008)

12 Osaka, I \& McCullough, R. D. Advances in molecular design and synthesis of regioregular polythiophenes. Acc. Chem. Res. 41, 1202-1214 (2008).

13 Yokozawa, T. \& Yokoyama, A. Chain-growth condensation polymerization for the synthesis of well-defined condensation polymers and $\pi$-conjugated polymers. Chem Rev. 109, 5595-5619 (2009).

14 Kiriy, A., Senkovskyy, V. \& Sommer, M. Kumada catalyst-transfer polycondensation: mechanism, opportunities, and challenges. Macromol. Rapid Commun. 32, 1503-1517 (2011)

15 Yokozawa, T., Nanashima, Y. \& Ohta, Y. Precision synthesis of n-type $\pi$-conjugated polymers in catalyst-tyransfer condensation polymerization. ACS Macro Lett. 1, 862-866 (2012).

16 Yokozawa, T., Nanashima, Y., Kohno, H., Suzuki, R., Nojima, M. \& Ohta, Y. Catalyst transfer condensation polymerization for precision synthesis of $\pi$-conjugated polymers. Pure Appl. Chem. 85, 573-587 (2013).

17 Yokozawa, T. \& Ohta, Y. Scope of controlled synthesis via chain-growth condensation polymerization: from aromatic polyamides to $\pi$-conjugated polymers. Chem. Commun 49, 8281-8310 (2013).

18 Bryan, Z. J. \& McNeil, A. J. Conjugated polymer synthesis via catalyst-transfer polycondensation (CTP): mechanism, scope, and applications. Macromolecules 46 8395-8405 (2013)

19 Murarka, S. \& Studer, A. Radical/anionic $\mathrm{S}_{\mathrm{RN}} 1$-type polymerization for preparation of oligoarenes. Angew. Chem. Int. Ed. 51, 12362-12366 (2012).

20 Iwatsuki, S. Polymerization of quinodimethane compounds. Adv. Polym. Sci. 58 93-120 (1984).

21 Iwatsuki, S. in The Chemistry of Quinoide Compounds, Vol. 2 (eds Patai, S. \& Rappoport, Z.) Ch. 18, 1068-1111 (Wiley, New York, NY, USA, 1988).

22 Greiner, A., Mang, S., Schäfer, O. \& Simon, P. Poly( $p$-xylylene)s: synthesis, polymer analogous reactions, and perspectives on structure-property relationships. Acta Polym 48, 1-15 (1997)

23 Itoh, T. \& Iwatsuki, S. Polymerization behavior of electron-accepting substituted quinodimethanes. Macromol. Chem. Phys. 198, 1997-2016 (1997).

24 Itoh, T. Polymerizations and polymers of quinonoid monomers. Prog. Polym. Sci. 26 1019-1059 (2001).

25 Itoh, T. Solution and solid-state polymerizations of substituted $p$-quinodimethanes and p-quinone methides. Polymer 46, 6998-7017 (2005).

26 Szwarc, $\mathrm{M}$. Some remarks on the $\mathrm{CH}_{2}=\mathrm{C}(\mathrm{CH}=\mathrm{CH})_{2} \mathrm{C}=\mathrm{CH}_{2}$ molecule. Discuss. Faraday Soc. 2, 46-49 (1947)

27 Gorham, W. F. A new, general synthetic method for the preparation of linear poly-p-xylylenes. J. Polym. Sci. A-1 4, 3027-3039 (1966).

28 Cho, I. \& Song, K. Y. Radical ring-opening polymerization of 10-methylene-9,10dihydroanthryl-9-spirocyclopropane. J. Polym. Sci. A Polym. Chem. 32, 1789-1791 (1994).

29 Mori, H., Masuda, S. \& Endo, T. Ring-opening RAFT polymerization based on aromatization as driving force: synthesis of well-defined polymers containing anthracene units in the main chain. Macromolecules 39, 5976-5978 (2006).
30 Mori, H., Masuda, S. \& Endo, T. Ring-opening copolymerization of 10-methylene9,10-dihydroanthryl-9-spirophenylcyclopropane via free radical and RAFT processes. Macromolecules 41, 632-639 (2008).

31 Mori, H., Tando, I. \& Tanaka, H. Synthesis and optoelectronic properties of alternating copolymers containing anthracene unit in the main chain by radical ring-opening polymerization. Macromolecules 43, 7011-7020 (2010).

32 Nakabayashi, K., Inoue, S., Abiko, Y. \& Mori, H. Polymers composed of alternating anthracene and pyridine containing units by radical ring-opening polymerization: controlled synthesis, optical properties, and metal complexes. Macromolecules 46 4790-4798 (2013).

33 Cho, I. \& Kim, W. T. Exploratory ring-opening polymerization. XII. polymerization of substituted spiro[2,5]octa-4,7-diene-6-ones and spiro[cyclopropane-1,4' (1'-naphthalenone)]. J. Polym. Sci. C Polym. Lett 24, 109-111 (1986).

34 Cho, I. \& Kim, W. T. Polymerization systems driven by aromatization energy: anionic polymerization of 4-allylidene-2,6-dimethyl-2,5-cyclohexadien-1-one and spiro[2,5] octadienone derivatives. J. Polym. Sci. A Polym. Chem 25, 2791-2798 (1987)

35 Hauser, C. F. \& Zutty, N. I. Quinone copolymerization. I. reactions of $p$-chloranil, p-benzoquinone, and 2,5-dimethyl-p-benzoquinone with vinyl monomers under freeradical initiation. J. Polym. Sci. A-1 8, 1385-1401 (1970).

36 Hauser, C. F. \& Zutty, N. I. Quinone copolymerization. III. reactions of 2,5,7, 10-tetrachlorodiphenoquinone, o-chloranil, and 2,3-dichloro-5,6-dicyano- $p$ benzoquinone with vinyl monomers under free-radical initiation. Macromolecules 4 478-482 (1971)

37 Iwatsuki, S. \& Itoh, T. Alternating copolymerization of 2,3-dichloro-5,6-dicyanop-benzoquinone with styrene and polymerization behavior with vinyloxy compounds. J. Polym. Sci. Polym. Chem. Ed 18, 2971-2982 (1980).

38 Iwatsuki, S., Itoh, T., Itoh, H. \& Kubo, M. Polymerization behavior of $N, 7$, 7-tricyanobenzoquinone methide imine. Macromolecules 23, 2423-2427 (1990).

39 Iwatsuki, S. \& Itoh, T. Polymerization behavior of $p$-quinone bis(benzenesulfonimide) as an acceptor monomer. Macromolecules 17, 1425-1431 (1984).

40 Itoh, T., Matsunaga, Y., Kubo, M. \& Iwatsuki, S. Amphoteric behavior of substituted p-benzoquinone diimines in alternating copolymerization. Macromolecules 28 6357-6360 (1995).

41 Vilbrandt, N., Nickel, S., Immel, S., Rehahn, M., Stegmaier, K., Melzer, C. \& von Seggern, H. Poly(para-phenylene vinylene)s in Materials Science and Technology, 901-922 (Wiley-VCH, Weinheim, Germany, 2013).

42 Grimsdale, A. C., Chan, K. L., Martin, R. E., Jokisz, P. G. \& Holmes, A. B. Synthesis of light-emitting conjugated polymers for applications in electroluminescent devices. Chem. Rev. 109, 897-1091 (2009).

43 Blayney, A. J., Perepichka, I. F., Wudl, F. \& Perepichka, D. F. Advances and challenges in the synthesis of poly( $p$-phenylene vinylene)-based polymers. Isr. J. Chem. 54, 674-688 (2014).

44 Lee, Y., Liang, Y. \& Yu, L. The Heck polycondensation for functional polymers. Synlett 18, 2879-2893 (2006).

45 Carsten, B., He, F., Son, H. J., Xu, T. \& Yu, L. Stille polycondensation for synthesis of functional materials. Chem. Rev. 111, 1493-1528 (2011).

46 Junkers, T., Vandenbergh, J., Adriaensens, P., Lutsen, L. \& Vanderzande, D. Synthesis of poly( $p$-phenylene vinylene) materials via the precursor routes. Polym. Chem. 3 275-285 (2012).

47 Conticello, V. P., Gin, D. L. \& Grubbs, R. H. Ring-opening metathesis polymerization of substituted bicyclo[2.2.2]octadienes: a new precursor route to poly(1, 4-phenylenevinylene). J. Am. Chem. Soc. 114, 9708-9710 (1992).

$48 \mathrm{Pu}, \mathrm{L}$., Wagaman, M. W. \& Grubbs, R. H. Synthesis of poly(1,4-naphthylenevinylenes): metathesis polymerization of benzobarrelenes. Macromolecules 29, 1138-1143 (1996).

49 Tasch, S., Graupner, W., Leising, G., Pu, L., Wagner, M. W. \& Grubbs, R. H. Red-orange electroluminescence with new soluble and air-stable poly(naphthalenevinylene)s. Adv. Mater. 7, 903-906 (1995).

50 Wagaman, M. W. \& Grubbs, R. H. Synthesis of PNV homo- and copolymers by a ROMP precursor route. Synth. Metals 84, 327-328 (1997).

51 Jones, R. R. \& Bergman, R. G. p-Benzyne. generation as an intermediate in a therma isomerization reaction and trapping evidence for the 1,4-benzenediyl structure. J. Am. Chem Soc 94, 660-661 (1972).

52 Kovacic, P. \& Jones, M. B. Dehydro coupling of aromatic nuclei by catalyst-oxidant systems: poly(p-phenylene). Chem. Rev. 87, 357-379 (1987).

53 Tour, J. M. Soluble oligo- and polyphenylenes. Adv. Mater. 6, 190-198 (1994).

54 Sander, W. m-Benzyne and p-benzyne. Acc. Chem. Res. 32, 669-676 (1999).

55 John, J. A. \& Tour, J. M. Synthesis of polyphenylenes and polynaphthalenes by thermolysis of enediynes and dialkynylbenzenes. J. Am. Chem. Soc. 116, 5011-5012 (1994).

56 Xiao, Y \& Hu, A. Bergman cyclization in polymer chemistry and material science. Macromol. Rapid Commun. 32, 1688-1698 (2011).

57 Sun, Q., Zhang, C., Li, Z., Kong, H., Tan, Q., Hu, A. \& Xu, W. On-surface formation of one-dimensional polyphenylene through Bergman cyclization. J. Am. Chem. Soc. 135 8448-8451 (2013)

58 Marvel, C. S. \& Hartzell, G. E. Preparation and aromatization of poly-1, 3-cyclohexadiene. J. Am. Chem. Soc. 81, 448-452 (1959).

59 Frey, D. A., Hasegawa, M. \& Marvel, C. S. Preparation and aromatization of poly-1,3cyclohexadiene. II. J. Polym. Sci. A 1, 2057-2065 (1963).

60 Lefebvre, G. \& Dawans, F. 1,3-Cyclohexadiene polymers. part I. preparation and aromatization of poly-1,3-cyclohexadiene. J. Polym. Sci. A 2, 3277-3295 (1964). 
61 Cassidy, P. E., Marvel, C. S. \& Ray, S. Preparation and aromatization of poly-1,3cyclohexadiene and subsequent crosslinking. III. J. Polym. Sci. A 3, 1553-1565 (1965).

62 Natori, I. Synthesis of polymers with an alicyclic structure in the main chain. Living anionic polymerization of 1,3-cyclohexadiene with the $n$-butyllithium/ $N, N, N^{\prime}, N^{\prime}$ tetramethylethylenediamine system. Macromolecules 30, 3696-3697 (1997).

63 Natori, I., Imaizumi, K., Yamagishi, H. \& Kazunori, M. Hydrocarbon polymers containing six-membered rings in the main chain. microstructure and properties of poly(1,3-cyclohexadiene). J. Polym. Sci. B Polym. Phys. 36, 1657-1668 (1998).

64 Natori, I \& Inoue, S. Anionic polymerization of 1,3-cyclohexadiene with alkyllithium/amine systems. characteristics of $n$-butyllithium/ $N, N, N^{\prime}, N^{\prime}$-tetramethylethylenediamine system for living anionic polymerization. Macromolecules 31, 4687-4694 (1998).

65 Hong, K. \& Mays, J. W. 1,3-Cyclohexadiene polymers. 1. anionic polymerization. Macromolecules 34, 782-786 (2001)

66 Natori, I. \& Sato, H. Oxidation of poly(1,3-cyclohexadiene): influence of the polymer chain structure. J. Polym. Sci. A Polym. Chem. 44, 837-845 (2006).

67 François, B. \& Zhong, X. F. Synthesis, characterization and doping of soluble diblock and triblock copolymers including polyparaphenylene sequences. Synth. Metals 41 955-958 (1991).

68 Widawski, G., Rawiso, M. \& François, B. Self-organized honeycomb morphology of star-polymer polystyrene films. Nature 369, 387-389 (1994).

69 François, B., Widawski, G., Rawiso, M. \& Cesar, B. Block-copolymers with conjugated segments: synthesis and structural characterization. Synth. Metals 69, 463-466 (1995).

70 Natori, I., Natori, S., Tsuchiya, K. \& Ogino, K. Synthesis of novel semiconducting polymers consisting of $p$-phenylene, $p$-phenylenevinylene, and styrylamine structures: copolymerization and dehydrogenation of 1,3-cyclohexadiene and 4-diphenylaminostyrene. Macromolecules 44, 256-262 (2011).

71 François, B., Izzillo, S. \& Iratçabal, P. Substituted PPV block copolymer from anionically prepared precursor. Synth. Metals 102, 1211-1212 (1999).

72 Ederlé, Y. \& Mathis, C. Grafting of anionic polymers onto $\mathrm{C}_{60}$ in polar and nonpolar solvents. Macromolecules 30, 2546-2555 (1997).

73 Mignard, E., Hiorns, R. C. \& François, B. Synthesis and characterization of star copolymers consisting of fullerene and conjugated polyphenylene: 6-star- $\mathrm{C}_{60}$ [styrene-poly(1,4-phenylene)-block-polystyrene] and 6-star- $\mathrm{C}_{60}$ [polystyrene-blockpoly(1,4-phenylene)]. Macromolecules 35, 6132-6141 (2002).

74 Ballard, D. G. H., Courtis, A., Shirley, I. M. \& Taylor, S. C. A biotech route to polyphenylene. J. Chem. Soc. Chem. Commun. 954-955 (1983).

75 Ballard, D. G. H., Courtis, A., Shirley, I. M. \& Taylor, S. C. Synthesis of polyphenylene from a cis-dihydrocatechol biologically produced monomer. Macromolecules 21 , 294-304 (1988).

76 McKean, D. R. \& Stille, J. K. Electrical properties of poly(5,6-dihydroxy-2-cyclohexen1,4-ylene) derivatives. Macromolecules 20, 1787-1792 (1987).

77 Gin, D. L., Conticello, V. P. \& Grubbs, R. H. Stereoregular precursors to poly( $p$-phenylene) via transition-metal-catalyzed polymerization. 1. precursor design and synthesis. J. Am. Chem. Soc. 116, 10507-10519 (1994).

78 Gin, D. L., Conticello, V. P. \& Grubbs, R. H. Transition-metal-catalyzed polymerization of heteroatom-functionalized cyclohexadienes: stereoregular precursors to poly $(p$ phenylene). J. Am. Chem. Soc. 114, 3167-3169 (1992).

79 Gin, D. L., Conticello, V. P. \& Grubbs, R. H. Stereoregular precursors to poly(p-phenylene) via transition-metal-catalyzed polymerization. 2 . the effects of polymer stereochemistry and acid catalysts on precursor aromatization: a characterization study. J. Am. Chem. Soc. 116, 10934-10947 (1994).

80 Fisher, I. P. \& Lossing, F. P. Ionization potential of benzyne. J. Am. Chem. Soc. 85, 1018-1019 (1963).

81 Berry, R. S., Clardy, J. \& Schafer, M. E. Decomposition of benzenediazonium-3carboxylate: transient 1,3-dehydrobenzene. Tetrahedron Lett. 6, 1011-1017 (1965).

82 Sander, W., Exner, M., Winkler, M., Balster, A., Hjerpe, A., Kraka, E. \& Cremer, D. Vibrational spectrum of $m$-benzyne: a matrix isolation and computational study. J. Am. Chem. Soc. 124, 13072-13079 (2002).

83 Stumetz, K. S., Nadeau, J. T. \& Cremeens, M. E. Potential nonadiabatic reactions: ring-opening 4,6-dimethylidenebicyclo[3.1.0]hex-2-ene derivatives to aromatic reactive intermediates. J. Org. Chem. 78, 10878-10884 (2013).

84 Rule, M., Matlin, A. R., Hilinski, E. F., Dougherty, D. A. \& Berson, J. A $m$-Quinomethane: synthesis of a covalent-biradicaloid pair of valence tautomers. J. Am. Chem. Soc. 101, 5098-5099 (1979).

85 Itoh, T., Matsumura, Y. \& Kubo, M. Polymerization of meta-naphthoquinone methide 3,4-benzo-6-methylenebicyclo[3.1.0]hex-3-ene-2-one. J. Polym. Sci. A Polym. Chem. 35, 741-746 (1997).

86 Segura, J. L. \& Martín, N. o-Quinodimethanes: efficient intermediates in organic synthesis. Chem. Rev. 99, 3199-3246 (1999).

87 Errede, I. A. The chemistry of xylylenes. X. some polymers and telomers of spiro-di-oxylylene. J. Polym. Sci. 49, 253-265 (1961).

88 Farona, M. F. Benzocyclobutenes in polymer chemistry. Prog. Polym. Sci. 21, 505-555 (1996).

89 Chino, K. \& Endo, T. Prediction of thermal isomerization temperatures of substituted benzocyclobutenes to $o$-quinodimethanes by semi-empirical molecular orbital calculation. Lett. Org. Chem. 8, 138-142 (2011).

90 Chino, K., Takata, T. \& Endo, T. Polymerization of o-quinodimethanes, 1. radical polymerization of 1-methoxy-o-quinodimethane formed in situ by thermal isomerization of 1-methoxy-benzocyclobutene. Macromol. Rapid Commun. 17, 339-345

(1996).

91 Chino, K., Takata, T. \& Endo, T. Polymerization of o-quinodimethanes bearing electron-donating groups in situ formed by thermal isomerization of benzocyclobutenes. Macromolecules 30, 6715-6720 (1997).

92 Chino, K. \& Endo, T. Polymerization of o-quinodimethanes. V. ionic polymerization of o-quinodimethanes generated by thermal isomerization of corresponding benzocyclobutenes. J. Polym. Sci. A Polym. Chem. 46, 844-850 (2008).

93 Chino, K., Takata, T. \& Endo, T. Polymerization of o-quinodimethanes. III. polymerization of o-quinodimethanes bearing electron-withdrawing groups formed in situ by thermal ring-opening isomerization of corresponding benzocyclobutenes. J. Polym. Sci. A Polym. Chem. 37, 1555-1563 (1999).

94 Chino, K. \& Endo, T. Polymerization of $o$-quinodimethanes. IV. radical polymerization of 1-cyano-o-quinodimethane in the presence of TEMPO. J. Polym. Sci. A Polym. Chem. 38, 3434-3439 (2000).

95 Chino, K., Takata, T. \& Endo, T. A novel group transfer polymerization of 1-trimethylsiloxybenzocyclobutene via hetero Diels-Alder reaction. Macromol. Rapid Commun. 17, 163-168 (1996).

96 Ito, Y., Ihara, E., Murakami, M. \& Shiro, M. New living polymerization of 1,2-diisocyanoarenes via (quinoxalinyl)palladium complexes. synthesis of poly(2,3-quinoxaline). J. Am. Chem. Soc. 112, 6446-6447 (1990).

97 Ito, Y., Ihara, E. \& Murakami, M. Enantioselective polymerization of 1 , 2-diisocyanoarenes-synthesis of optically active, helical poly(quinoxaline-2,3-diyl)s. Angew. Chem. Int. Ed. Engl. 31, 1509-1510 (1992).

98 Suginome, M., Yamamoto, T. \& Nagata, Y. Poly(quinoxaline-2,3-diyl)s: a fascinating helical macromolecular scaffold for new chiral functions. J. Synth. Org. Chem. Jpn. 73, 1141-1155 (2015).

99 Suginome, M., Yamamoto, T., Nagata, Y., Yamada, T. \& Akai, Y. Catalytic asymmetric synthesis using chirality-switchable helical polymer as a chiral ligand. Pure Appl. Chem. 84, 1759-1769 (2012)

100 Yamamoto, T., Akai, Y. \& Suginome, M. Chiral palladacycle catalysts generated on a single-handed helical polymer skeleton for asymmetric arylation ring opening of 1,4-epoxy-1,4-dihydronaphthalene. Angew. Chem. Int. Ed. 53, 12785-12788 (2014)

101 Ke, Y.-Z., Nagata, Y., Yamada, T. \& Suginome, M. Majority-rules-type helical poly (quinoxaline-2,3-diyl)s as highly efficient chirality-amplification systems for asymmetric catalysis. Angew. Chem. Int. Ed. 54, 9333-9337 (2015).

102 Nagata, Y., Yamada, T., Adachi, T., Akai, Y., Yamamoto, T. \& Suginome, M. Solvent-dependent switch of helical main-chain chirality in sergeants-and-soldierstype poly(quinoxaline-2,3-diyl)s: effect of the position and structures of the "sergeant" chiral units on the screw-sense induction. J. Am. Chem. Soc. 135, 10104-10113 (2013)

103 Nagata, Y., Nishikawa, T. \& Suginome, M. Poly(quinoxaline-2,3-diyl)s bearing (S)-3-octyloxymethyl side chains as an efficient amplifier of alkane solvent effect leading to switch of main-chain helical chirality. J. Am. Chem. Soc. 136, 15901-15904 (2014).

104 Nagata, Y., Nishikawa, T. \& Suginome, M. Exerting control over the helical chirality in the main chain of sergeants-and-soldiers-type poly(quinoxaline-2,3-diyl)s by changing from random to block copolymerization protocols. J. Am. Chem. Soc. 137 , 4070-4073 (2015)

105 Nagata, Y., Takeda, R. \& Suginome, M. Pressure-dependent helix inversion of poly (quinoxaline-2,3-diyl)s containing chiral side chains in non-aqueous solvents. Chem. Commun. 51, 11182-11185 (2015).

106 Shintani, R., lino, R. \& Nozaki, K. Rhodium-catalyzed polymerization of 3,3-diarylcyclopropenes involving a 1,4-rhodium migration. J. Am. Chem. Soc. 136, 7849-7852 (2014).

107 Stoermer, R. \& Kahlert, B. Ueber das 1- und 2-brom-cumaron. Ber. Dtsch. Chem. Ges. 35, 1633-1640 (1902)

108 Wenk, H. H., Winkler, M. \& Sander, W. One century of aryne chemistry. Angew. Chem. Int. Ed. 42, 502-528 (2003).

109 Hoffmann, R. W. Dehydrobenzene and Cycloalkyne (Academic Press, New York, NY, USA, 1967).

110 Pellissier, H. \& Santelli, M. The use of arynes in organic synthesis. Tetrahedron 59, 701-730 (2003).

111 Sanz, R. Recent applications of aryne chemistry to organic synthesis. a review. Org. Prep. Proced. Int. 40, 215-291 (2008).

112 Pérez, D., Peña, D. \& Guitián, E. Aryne cycloaddition reactions in the synthesis of large polycyclic aromatic compounds. Eur. J. Org. Chem. 5981-6013 (2013)

113 Ihara, E., Kurokawa, A., Koda, T., Muraki, T., Itoh, T. \& Inoue, K. Benzyne as a monomer for polymerization: alternating copolymerization of benzyne and pyridine to give novel polymers with o-phenylene and 2,3-dihydropyridine units in the main chain. Macromolecules 38, 2167-2172 (2005).

114 Mizukoshi, Y., Mikami, K. \& Uchiyama, Y. Aryne polymerization enabling straightforward synthesis of elusive poly(ortho-arylene)s. J. Am. Chem. Soc. 137, 74-77 (2015).

115 Lautens, M. Ring opening reactions of oxabicyclic compounds as a route to cyclic and acyclic compounds with multiple stereocenters. Synlett 177-185 (1993).

116 Chiu, P. \& Lautens, M. Using ring-opening reactions of oxabicyclic compounds as a strategy in organic synthesis. Top. Curr. Chem. 190, 1-85 (1997).

117 Lautens, M., Fagnou, K. \& Hiebert, S. Transition metal-catalyzed enantioselective ring-opening reactions of oxabicyclic alkenes. Acc. Chem. Res. 36, 48-58 (2003).

118 Rayabarapu, D. K. \& Cheng, C.-H. New catalytic reactions of oxa- and azabicyclic alkenes. Acc. Chem. Res, 40, 971-983 (2007). 
119 Safir, A. L. \& Novak, B. M. Air- and water-stable 1,2-vinyl-insertion polymerizations of bicyclic olefins: a simple precursor route to polyacetylene. Macromolecules 26 4072-4073 (1993)

120 Safir, A. L. \& Novak, B. M. Living 1,2-olefin-insertion polymerizations initiated by palladium(II) alkyl complexes: block copolymers and a route to polyacetylenehydrocarbon diblocks. Macromolecules 28, 5396-5398 (1995).

121 Zhang, S.-W. \& Takahashi, S. Rhodium-catalyzed copolymerization of norbornadiene derivatives with carbon monoxide. Chem. Commun. 315-316 (2000).

122 Zhang, S.-W., Kaneko, T. \& Takahashi, S. Rhodium-catalyzed copolymerization of norbornadienes and norbornenes with carbon monoxide. Macromolecules 33 6930-6936 (2000)

123 Peng, F., Fan, B., Shao, Z., Pu, X., Li, P. \& Zhang, H. Cu(OTf) - $_{\text {-catalyzed }}$ isomerization of 7-oxabicyclic alkenes: a practical route to the synthesis of 1-naphthol derivatives. Synthesis 3043-3046 (2008).

124 Ballantine, M., Menard, M. L. \& Tam, W. Isomerization of 7-oxabenzonorbornadienes into naphthols catalyzed by $\left[\mathrm{RuCl}_{2}(\mathrm{CO})_{3}\right]_{2}$. J. Org. Chem. 74, 7570-7573 (2009).

125 Ito, S., Takahashi, K. \& Nozaki, K. Formal aryne polymerization: use of [2.2.1] oxabicyclic alkenes as aryne equivalents. J. Am. Chem. Soc. 136, 7547-7550 (2014).

126 Walter, M. D., Moorhouse, R. A., Urbin, S. A., White, P. S. \& Brookhart, M. $\gamma$-Agostic species as key intermediates in the vinyl addition polymerization of norbornene with cationic (allyl)Pd catalysts: synthesis and mechanistic insights. J. Am. Chem. Soc. 131, 9055-9069 (2009).

127 Ito, S., Wang, W., Nishimura, K. \& Nozaki, K. Formal aryne/carbon monoxide copolymerization to form aromatic polyketones/polyketals. Macromolecules 48 1959-1962 (2015).

128 Yonezawa, N. \& Okamoto, A. Synthesis of wholly aromatic polyketones. Polym. J. 41 899-928 (2009)

129 Mullins, M. J. \& Woo, E. P. The synthesis and properties of poly(aromatic ketones). J. Macromol. Sci. Rev. Macromol. Chem. Phys. C27, 313-341 (1987).

130 Yang, J. \& Gibson, H. W. Polyketone synthesis involving nucleophilic substitution via carbanions derived from bis( $\alpha$-amino nitrile)s. 2. wholly aromatic polyketones without ether linkages. Macromolecules 30, 5629-5633 (1997).

131 Gibson, H. W. \& Dotson, D. L. Wholly aromatic polymeric ketones from bis-( $\alpha$-aminonitrile)s via soluble poly(bisaminonitrile)s. Polymer 39, 6483-6487 (1998)

132 Yang, J. \& Gibson, H. W. A polyketone synthesis involving nucleophilic substitution via carbanions derived from bis( $\alpha$-aminonitrile)s. 5. a new, well-controlled route to "long" bisphenol and activated aromatic dihalide monomers. Macromolecules 32, 8740-8746 (1999).

133 Yonezawa, N., Miyata, S., Nakamura, T., Mori, S., Ueha, Y. \& Katakai, R. Synthesis of wholly aromatic polyketones using 2,2'-dimethoxybiphenyl as the acyl-acceptant monomer. Macromolecules 26, 5262-5263 (1993).
134 Yonezawa, N., Ikezaki, T., Nakamura, H. \& Maeyama, K. Successful synthesis of wholly aromatic polyketones via nickel-mediated aromatic coupling polymerization. Macromolecules 33, 8125-8129 (2000).

135 Drent, E. \& Budzelaar, P. H. M. Palladium-catalyzed alternating copolymerization of alkenes and carbon monoxide. Chem. Rev. 96, 663-681 (1996).

136 Nakamura, A., Ito, S. \& Nozaki, K. Coordination-insertion copolymerization of fundamental polar monomers. Chem. Rev. 109, 5215-5244 (2009).

137 Ito, S. \& Nozaki, K. Coordination - insertion copolymerization of polar vinyl monomers by palladium catalysts. Chem. Rec. 10, 315-325 (2010).

138 Nakamura, A., Anselment, T. M. J., Claverie, J., Goodall, B., Jordan, R. F., Mecking, S., Rieger, B., Sen, A., van Leeuwen, P. W. N. M. \& Nozaki, K. Ortho-phosphinobenzenesulfonate: a superb ligand for palladium-catalyzed coordination-insertion copolymerization of polar vinyl monomers. Acc. Chem. Res. 46, 1438-1449 (2013).

139 Carrow, B. P. \& Nozaki, K. Transition-metal-catalyzed functional polyolefin synthesis: effecting control through chelating ancillary ligand design and mechanistic insights. Macromolecules 47, 2541-2555 (2014).

140 Ito, S., Wang, W. \& Nozaki, K. Formal aryne/ethylene copolymerization to form polyethylene containing o-arylene units in the main chain. Polym. J. 47, 474-480 (2015).

141 Ito, S., Munakata, K., Nakamura, A. \& Nozaki, K. Copolymerization of vinyl acetate with ethylene by palladium/alkylphosphine-sulfonate catalysts. J. Am. Chem. Soc. 131, 14606-14607 (2009).

142 Ito, S., Kanazawa, M., Munakata, K., Kuroda, J., Okumura, Y. \& Nozaki, K. Coordination-insertion copolymerization of allyl monomers with ethylene. J. Am. Chem. Soc. 133, 1232-1235 (2011).

143 Ota, Y., Ito, S., Kuroda, J., Okumura, Y. \& Nozaki, K. Quantification of the steric influence of alkylphosphine-sulfonate ligands on polymerization, leading to highmolecular-weight copolymers of ethylene and polar monomers. J. Am. Chem. Soc. 136, 11898-11901 (2014).

144 Johnson, L. K., Mecking, S. \& Brookhart, M. Copolymerization of ethylene and propylene with functionalized vinyl monomers by palladium(II) catalysts. J. Am. Chem. Soc. 118, 267-268 (1996).

145 Mecking, S., Johnson, L. K., Wang, L. \& Brookhart, M. Mechanistic studies of the palladium-catalyzed copolymerization of ethylene and $\alpha$-olefins with methyl acrylate. J. Am. Chem. Soc. 120, 888-899 (1998).

146 Younkin, T. R., Connor, E. F., Henderson, J. L., Friedrich, S. K., Grubbs, R. H. \& Bansleben, D. A. Neutral, single-component nickel (II) polyolefin catalysts that tolerate heteroatoms. Science 287, 460-462 (2000).

147 Carrow, B. P. \& Nozaki, K. Synthesis of functional polyolefins using cationic bisphosphine monoxide-palladium complexes. J. Am. Chem. Soc. 134, 8802-8805 (2012).

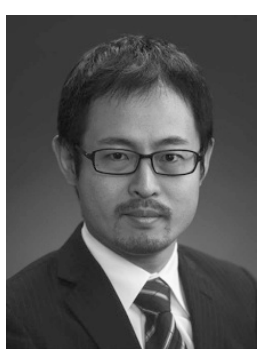

Dr Shingo Ito was born in 1981 in Nagoya, Japan. He received his $\mathrm{PhD}$ degree in 2008 from the University of Tokyo under the supervision of Professor Eiichi Nakamura. During that time, he joined the group of Professor Scott E. Denmark at University of Illinois at Urbana-Champaign and the group of Professor Masaharu Nakamura at Kyoto University as a predoctoral researcher. In 2008, he became an assistant professor at the Department of Chemistry and Biotechnology, Graduate School of Engineering, the University of Tokyo, Tokyo, Japan. He received the Sanyo Chemical Industries Award in Synthetic Organic Chemistry, Japan (2008), the Award for Encouragement of Research in Polymer Science, the Society of Polymer Science, Japan (2014) and the 29th Young Scholar Lectures of CSJ (2015). His research interests include the development of novel synthetic methods for functional polymers and aromatic compounds. 